\title{
Translation and Dissemination of Chinese Dietary Culture with the Belt and Road Initiative
}

\author{
Yan Miao \\ Shanxi Normal University, China
}

\begin{abstract}
Based on ancient Silk Road, China President Xi Jinping has proposed the Belt and Road Initiative, which is related to the dietary culture closely. Dietary culture translation is a necessary way to disseminate culture, becoming more and more important. Proper translations will show foreigners profound cultural connotation about China dietary. The author will adopt the methods of literature review and comparative, and point out translation difficulties and strategies for the cultural communication and transmission in the paper. The paper is divided into four parts. Firstly, the author will introduce the Belt and Road Initiative and China dietary culture. Secondly, the author will point out its status and difficulties under the background of the Belt and Road Initiative. Thirdly, the author will put forward some translation strategies about Chinese dietetic culture. Finally, the author will summarize the passage and the limitations of paper.
\end{abstract}

Index Terms - the Belt and Road Initiative, dietetic culture, cultural transmission, translation strategies

\section{INTRODUCTION}

The Belt and Road Initiative is a necessary way of culture exchange, shifting China's situation from the passive adaptation to the active guidance in the tide of globalization. But its developmental process is not plain sailing, Chinese confronted with many risks and challenges at home and aboard. So, the topic about how to carry out the Belt and Road Initiative and explore a new global path with Chinese characters is vital to China. The author will focus on the translation difficulties that Chinese dietary culture 'going out' in the paper. With the development of the Belt and Road Initiative, more and more foreigners pay attention to the Chinese culture, promoting external exchange of Chinese dietary culture. So the proper translation of Chinese food names will help foreigners understand Chinese food culture. The English translation of Chinese food names have been studied in recent years, but present situation is still unsatisfactory for the learners do not explore deeply in this field. Translators must take on the responsibility to introduce and disseminate Chinese dietary culture. Only in this way, can the foreigners understand the connotation of Chinese dietary culture accurately. Based on the summary about translation difficulties of Chinese dietary culture, the author will point out its present situation, analyze the feasibility of optimizing translation and provide some translation strategies in this paper.

\section{RESEARCh SignificANCE}

With the development of the Belt and Road Initiative, the Chinese dietary culture stepping out of China gradually and attracting more and more foreign learners to research, providing a valuable opportunity for disseminating Chinese food culture. Therefore, the proper translation about the Chinese food name becomes more necessary and important. The translation of Chinese dietary names not only help foreigners understand Chinese food better, but also disseminate Chinese food culture. Although many scholars have studied translation on Chinese dish names in recent years, its present situation is still unsatisfactory and confusing. Therefore, researching and studying the translation principles and strategies about Chinese dietary culture is necessary and vital.

\section{LITERATURE REVIEW}

The Researches about translation on Chinese dietary culture are numerous and multiple, but the learners do not have an agreement on this topic, yet. Viewpoints in present situation are roughly divided into the following parts: literal translation or paraphrase, domestication or foreignization, source-oriented or target-oriented, author-centered or translator-centered, reader-centered on the source language or the target language, form or content, functional equivalence or formal equivalence. To some extent, these foreign translation theories have broadened horizons of domestic scholars. Zhao Jingchen (1984) advocated that expressiveness is better than faithfulness in the translation process. He argued that translation makes the target readers understand the original text and acquire certain knowledge and entertainment from it (Zhao, 1984). In the 1960s, Qian Zhongshu (1960) putted forward the sublimation theory in Lin Shu's Translation; he advocated that the translators should not pursue the faithfulness of original text blindly, because this translation method may reduce the readability of articles (Qian, 1960).

With the development of foreign translation theories, Eugene A. Naida (1986), J. C. Catford (1965), Peter Newmark (1988) and George Steiner (1975) all putted forward their different viewpoints on translation in the 1980s. For example, 
Steiner George (1975) thought that translation should be centered on the ideological meaning expressed by the original author; the translators should not tamper with the original author's intention (George, 1975). Peter Newmark (1988) putted forward the semantic translation and communicative translation in Approaches to Translation (Newmark, 1988). Then, Eugene A. Naida (1986) proposed Functional Equivalence based on the predecessor's researches in From One Language to Another (Naida, 1986). These theories have triggered the fourth translation climax in China. A large number of outstanding translators have emerged in China. For example, Gu Zhengkun (1989) has proposed that translation criteria are pluralistic and complementary in the pluralistic and complementary translation criteria $(\mathrm{Gu}$, 1989).

The core idea of Functional Equivalence is functional equivalence between the source and target language. Eugene A. Nida (1982) advocated that translators should not only consider information transfer, but also the cultural difference, social value and readerships in The Theory and Practice of Translation (Nida \& Taber, 1982). In intercultural translation, the most important thing is to make the translation reproduce the intrinsic information and basic connotation of the source text effectively. The translators should focus on the writing styles of source and target language, avoiding translationese in the process of translation.

\section{Chinese Dietary Culture with “One Belt and One Road” Initiatives}

Xi Jinping putted forward the concept of the Belt and Road Initiative in 2013. Then the National Development and Reform Commission and the Ministry of Foreign Affairs jointly issued of Building the Silk Road Economic Belt and $21^{\text {st }}$ Century Maritime Silk Road. The Belt and Road Initiative is the inevitable requirement of realizing the comprehensive rejuvenation of China, shifting China's situation from the passive adaptation to the active guidance in the tide of globalization. However, its construction process was not smooth sailing, and China will encounter with various risks and crisis at home and aboard inevitably. Based on the descriptions above, the author will discuss the difficulties and challenges about the translation on Chinese dietary culture in this paper.

The Belt and Road Initiative with dietary culture refers to material and spiritual wealth created by people along Silk Road in the process of food production and consumption. It includes the local diet culture along Silk Road and the new culture produced in the process of cultural exchange and integration. The ancient Silk Road is a trade way between China and foreign countries, the major imported and exported trade products along the ancient Silk Road were related to the dietary culture. The Belt and Road Initiative is related to the exchange and dissemination of Chinese dietary culture closely too.

All in all, the Belt and Road Initiative promotes the external exchange and dissemination of Chinese dietary culture. On the contrary, its external communication and dissemination promotes the construction and implementation of the Belt and Road Initiative, enhances the national cultural soft power and strengthens national cultural self-confidence,.

\section{The Translation of Chinese Dietary Culture with the Belt and Road Initiative}

\section{A. Characters of Chinese Dietary Culture}

China is an ancient civilization, dietary culture is enhanced. Chinese dietary culture has the following characteristics: firstly, various flavors; secondly, seasonal foods; thirdly, aesthetic sense on the dishes; fourthly, moral tales on the foods; finally, the combination of medicine and foods. Due to the dishes are named after materials and cooking methods in Western, translators should combine Chinese dishes characters with thinking habits of Westerners in the translation process.

\section{B. Differences in Dietary Culture between China and Western Countries}

\section{Lexical Vacancy}

Lexical vacancy refers to a cultural phenomenon that there is no corresponding words in target culture to express the unique object (physical or spiritual, concrete or abstract) in original culture, such as, steamed bun, dumpling, and rice noodles, which all are unique foods in Chinese dietary culture and there is no corresponding foods in Western countries. And, some Chinese dishes contain specific connotation, such as Soysauced Dongpo Pork and Dragon's Beard Noodles, Westerners cannot understand what these two dishes mean if they do not familiar with Chinese dietary culture, they just understand the two dishes according to the literal meaning.

2. Differences in cultural background

Diet is more important for Chinese; a lot of Chinese idioms are related to dietary culture. For example, “吃......饭” in Chinese is translated "make a living" in English. However, its translation is different in the specific cultural background. For example, the equivalent translation of “吃政治饭”is “to make a living by going for politics”; “吃算盘 子"should be translated into "to make a living by doing business".

\section{The Current Situation of English Translation of Chinese Dietary Culture}

China National Knowledge Infrastructure has collected 682 relevant domestic literature by searching for the English translation of dietary culture. Among them, there are 224 papers on language strategy, 164 papers on language theory, and 8 papers on cultural turn. China National Knowledge Infrastructure has collected 39 relevant foreign language 
literature, including the study about dietary culture translation based on functional strategy.

Domestic studies are centred on the topic: how to translate Chinese dish names into English effectively, so that Westerners can understand the profound cultural connotations of Chinese dietary culture. Foreign scholars focus on the topic: how to learn traditional Chinese food culture. At present, there are many studies about Chinese traditional dish names at home and abroad, but those articles only discussed this topic in general, providing a practical basis and research space for this study.

The author found many problems about Chinese dietary culture translation in the process external exchange. The first problem is excessive literal translation. If translators do not consider the cultural connotations of the original texts, the English translation cannot represent the aesthetic sense of dish names. Secondly, the translation fails to express the meaning of original words. Some translators do not consider cultural factors in the process of translation, causing difficulties for foreign readers to understand Chinese dishes. Thirdly, cultural blanks lead to misunderstanding. Due to the different culture, translators often fail to look for the corresponding items in the English and translate objects with their own understanding, making the foreigners difficult to understand the emotion expressed by the original author. Abdel Lefevere (1996) proposed the cultural turn in Translation - History, culture; He thought that translators not only pay attention on language conversion, but also its role and influence in the process of translation (Lefevere, 1996). In other words, translators should learn and understand the deep relationship between source and the target language from aspect of culture.

\section{Main Problems in Translation about Chinese Dietary Culture}

To some extent, the phenomenon of cultural discount is main problems in the process of dissemination on Chinese dietary culture. He Jianping and Zhao Yigang said: "Cultural discount is a value discount phenomenon of cultural products for cultural differences in international trade" in The Research on Cultural Discount in Chinese and Western Documentary Films (He \& Zhao, 2007, P.103). The different cultural structures make China's cultural products difficult to export to the Western countries. How to eliminate these obstacles is the main problem discussed in this paper. So the author will discuss further this topic according to three questions mentioned above.

1. Overliteral translation

Lefevere (1996) thought that there was no translation strategy can achieve complete equivalence in translation (Lefevere, 1996). Translators adopt word-for-word translation strategy to translate characteristic culture-loaded words, which will influence the expression of original connotation. For example, Li Na (2016) pointed out that flexible translation methods, techniques and strategies are adopted for highlighting the overlapping parts of the two cultures in subtitle translation of A Bite of China and reducing cultural discounts effectively (Li, 2016).

Example 1:

ST: 舌尖上的中国

TT1: Tip of Tongue/Eating in China/The Chinese Cui-sine

TT2: A Bite of China

The translation of Tip of Tongue will confuse western readers, because Tongue means speaking a language when it used as a noun. The "cultural turn" strategy emphasizes transcending the formal scope of pure language into a broader and deeper cultural level. The translation of Eating in China and The Chinese Cuisine reaches the equivalence with original text but lost the rhetorical effect of the original.

\section{Improper meaning}

Each national culture formed a certain style and tradition in the course of historical development. English and Chinese are different language in grammatical structure and ways of expressing ideas. The translation texts must be faithful to the original text and the expression habits of the target language. Therefore, translators should avoid the phenomenon of improper meanings caused by cultural blanks, analyze the original text from various angles and look for the deep cultural connotation.

Example 2:

ST: (人的迁徙促成了食物的相逢, 食物的离合见证了人聚散。然而究竟是人改变了食物, 还是食物改变了人?) 餐桌边的一蔬一饭, 舌尖上的一饮一啄, 总会为我们津津有味地, 一一道来。

TT: The meals on the table / and the taste on the tip of the tongue / will always racially tell us / everything.

Through the literal meaning of the words or phrases, even the whole sentence, the translator extended the meaning of the diet culture in daily life appropriately. “一蔬一饭” is the most common foods on the table, “一饮一啄” represents the taste of foods; two both are four-character idiom that represents the relationship between human and daily foods in a quiet, simple intonation, improving the quality of original articles. On the contrary, these two four-character words are difficult to understand for the target readers, translators should translate them properly for foreigners.

3. Cultural blanks

Language is a reflection of culture. The differences in the linguistic expressions result in cultural vacancies which are an important to the researches about translation strategies on traditional Chinese dietary culture and reflected in grammar, semantics and culture.

Example 3:

ST: 交通不便的年代, 人们远行时, 会携带能长期保存的食物, 它们被统称为路菜。 
TT: Transportation was inconvenient in the old days. When people travel, they will bring long-term preservation of food. Those foods are known as "road dishes".

In order to disseminate Chinese dietary culture in process of cultural self-confidence construction, the "road dishes" in the examples conforms to the English expression habits but lost cultural connotation, which can not realize true cultural dissemination and communication. For example, “馕” was translated into Nang, “泡馍” was translated into steamed bun, and “肉夹馍” translated into Chinese Hamburger in English. Those translation examples cannot convey the connotation of Chinese food culture fully.

\section{The Translation Strategies and Skills of Chinese Dietary Culture}

As the saying goes, "Food is the paramount necessity of the people". Although foods are important for Chinese and Westerners, there are also great differences about dietary culture between China and western countries for different dietary patterns and cooking methods. In the current trend of global economic and cultural exchange, cross-cultural communication has become a hot topic in the world. For foreign language learners, it is necessary to understand the differences between China and Western culture. The author will elaborate the translation strategies and skills of dietary culture based on cultural difference between China and Western countries.

\section{A. Translation Strategies about Chinese Dietary Culture}

According to the different orientations of translators, Xiong Bing (2014) divided translation strategies into foreignization strategy and domestication strategy. (Xiong, 2014). After analyzing the three major translation problem of Chinese traditional dietary culture, the translators should combine the "cultural turn" theory with the background of Chinese culture 'going out'.

\section{Application of domestication strategy}

The value of the source language culture should not be imposed on the target language excessively in the process of translation, and the translation should be conformed to English expression habits for avoiding the problem of "out of context, and over-literal translation” in translation. For example, 《舌尖上的中国》 is translated into A Bite of China by adopting the free translation strategy and domestication strategy, this translation example not only retain the semantics and rhetoric forms of the source language, but also help the target language readers to understand what the source language want to express deeply. Domestication strategy is often adopted in translation for avoiding cultural conflicts. But, cultural background should not be taken into account in the translation on Chinese dish names for different associative effects overly.

\section{Application of Foreignization Strategy}

Translators should have a through comprehension about the four-character idioms and other words with profound connotation used commonly by Chinese, and try best to retain the original artistic conception and resonates with target language readers. According to the core idea of cultural turn, the translation of the source language is guided by the linguistic habits and cultural traditions of the target language. Liu Caixia (2015) proposed that translators should not decay the Chinese culture for catering to the interests of foreigners; Chinese traditional dietary culture and customs is root, all translation should be based on this original culture. (Liu, 2015)

\section{B. Translation Skills}

Based on the analysis above, there are many differences between Chinese and Western culture. Therefore, translators must master certain translation skills when recommend Chinese dishes to foreign guests in English. According to different dish names, translators should grasp certain emphasis in dish names so that foreign guests can not only learn the dishes, but also understand its special connotation as much as possible.

\section{Name after lucky name}

There are many Chinese dishes named after allusions or lucky names. When translate these dishes names, translators should try best to show the main materials or cooking methods of dishes for foreigners, and take account of rhetoric of original text as much as possible rather than be restricted by the original name. Chinese often quote inedible items or animals that are forbidden to eat in Western countries to express good fortune in dish names, for example, “红烧狮子 头”, “翡翠菜心”. Of course, the lion's head is a Chinese food that Westerners will never eat. Chinese quote majestic head of lion to metaphor round and solid meatballs. And Jadeite is artistic symbol rather than jadeite in reality. Therefore, it is better to translate them according to their deep cultural meaning, so that Westerners can understand the cultural connotation of the dishes. As for the Chinese dish Mapo Tofu, it is a famous dish circulated in Sichuan Province widely and is famous for its color, aroma and taste. It is said that this dish was cooked by an old woman with many pockmarks on her face. However, Westerners do not know the allusions and cultural background when they taste this dish, so translators cannot translate it as a pock-marked woman's bean curd literally. On the country, they should focus on the description of the special taste of this dish for helping Westerners to understand the cultural connotation of the dish.

\section{Name after cooking methods}

As one of the most core elements of dietary culture, the translation and expression about cooking methods could help Westerners understand the Chinese dishes easily. However, many cooking methods of Chinese foods are not applied in 
Western cuisine commonly for different food habits. For example, "dry fried" is a cooking method that fries foods with little oil slowly. So in terms of the translation of “干煸牛肉丝”, translators should look for similar cooking methods in Western dietary culture and pick out the most proper method among them. After researching cooking methods in Western dietary culture, the author found that there are two kinds of similar methods as "dry fried" in Western. The first kind cooking methods contain baking, basting and roasting; the second kind of cooking methods include deep-frying, pan-frying and saut. From the cooking process of the dish, "saut" is more appropriate than those methods, it means that foods are fried quickly in a pan with a little hot butter or other fat in Western dietary culture. So, “煸牛肉丝” should be translated as sauted beef shreds.

\section{Name after special flavors}

Flavor dishes are widely spread and posses its greatest attraction in Chinese dietary culture. Therefore, in terms of the translation of dishes named for special flavor, translators not only show the original materials, but also its flavor characters in translation as far as possible. For example, as a kind of unique flavor, the translation of “鱼香肉丝” is very important and necessary. “鱼香肉丝” refers to a dish was made similar flavor as fishes by matching the changeless raw materials. Therefore, the name of this dish should not be translated into fish-flavor shred-deed pork but fried pork with garlic sauce or stir-fried pork shred in garlic sauce. Similarly, “糖醋排骨” should be translated as fried pork chop in sweet-sour sauce by similar translation strategy.

\section{Name after national characters}

China has a long history of cuisine culture, raw materials and cooking methods are various. Some Chinese dishes are unique in their names and have very strong national characters. Therefore, translators should adopt transliteration strategy and show the local characters of the target language from the perspective of cross-cultural communication. So the words or phrases in these dishes can be transliterated directly, helping foreign guests understand those dishes and retaining the cultural connotation of Chinese traditional dietary culture. For example, “炒面” should be translated directly as Chow Mein, “汤圆” can be translated directly as Tang Yuan, “馄饨” can be translated as Won Ton, “锅贴” can be translated as Kuo Tieh.

\section{CONCLUSION}

\section{A. Summary}

Chinese dietary culture is unique and charming in the world. It is incomparable with any other dietary culture for its profound cultural background and connotation. With the development of external cultural and economic exchange, it is more important to introduce Chinese dietary culture to the world. Although it is a great and arduous task, all Chinese should make joint efforts to disseminate the unique Chinese dietary culture to Western countries.

Under the background of cultural exchange between China and Western countries, the president Xi Jinping putted forward the Belt and Road Initiative which shows the new characters of Chinese dietary culture for foreigners. But it is difficult to make foreigners understand the Chinese dishes by adopting translation strategies. The author analyzed the main problems and the possibility of translating Chinese traditional dietary culture in the paper. Chinese dietary culture need to be recognized by different readers who do not familiar with Chinese culture. Therefore, it is necessary to study the translation strategies on Chinese traditional food culture. Based on the cultural difference between China and Western countries, translators should not only learn the Chinese dietary culture sufficiently, but also choose the appropriate translation strategies according to different ways of naming dishes, so that foreign guests can taste Chinese cuisine and understand the cultural connotation contained in the Chinese dishes, which is the ultimate goal of translation in cross-cultural communication.

\section{B. Limitations of the Study}

Due to the limited times and knowledge shortage of the author, this paper is far away from being perfect. There are still limitations which should be noticed.

There are inadequate understandings of the translation strategies in the paper for the hasty research time. The practical translation strategies are proved to be theoretical for translation practices. There is still a long process to discuss the applicability of those translation strategies about Chinese dietary culture. There are still derivative theories being used for such researches.

Many translation strategies and skills about Chinese dietary culture discussed by the author just touch the tip in this filed. There are still many other translation methods are not discussed in this paper. Therefore, the author will try best to research and study on the topic that how to convey cultural connotation in the process of translation and contribute to the dissemination of Chinese dietary culture in the future.

\section{REFERENCES}

[1] Abdel Lefevere. (1996). Translation - History, culture: A Sourcebook. London: Continuum International Publishing Group Ltd (New edition).

[2] Eugene A. Nida. (1986). From One Language to Another. N.Y: Thomas Nelson Inc.

[3] Eugene A. Nida \& Charles R. Taber. (1982). The Theory and Practice of Translation. Leiden: E.J. Brill. 
[4] George Steiner. (1975). After Babel. London: Oxford University Press

[5] Gu Zhengkun. (1989). The Pluralistic and Complementary Translation Criteria. Chinese Translation. 1, 16-20.

[6] He Jianpin \& Zhao Yigang. (2007). The Research on Cultural Discount in Chinese and Western Documentary Films. Modern communication. 146(3), 100-104.

[7] Liu Caixia. (2015). A Research on the Translation of National Characteristic Dishes. Chinese Translation. 1, 110-113.

[8] Li Na. (2016). Cultural Discount Phenomenon and Its Countermeasure. Social Sciences Review. 1, 118-122.

[9] Peter Newmark. (1988). Approaches to Translation. N.Y: Prentice Hall Inc.

[10] Qian Zhongshu. (1960). Lin Shu's Translation. Beijing: Higher Education Press.

[11] Xiong Bing. (2014). The Confused Concept in Translation-Cases in Translation Strategy, Method and Skills. Chinese Translation. 4, 82-88.

[12] Zhao Jingchen. (1984). The Collection on Translation Studies. Beijing: Foreign Language Teaching and Research Press.

Yan Miao was born in Shanxi, China in 1990. She graduated from North University of China in 2001. She is currently a postgraduate in Shanxi Normal University, China. Her major is English Translation. 